\title{
Performance of Chlorella sorokiniana under simulated extreme winter conditions
}

\author{
María Cuaresma Franco • Marieke F. Buffing • \\ Marcel Janssen • Carlos Vílchez Lobato • \\ René H. Wijffels
}

Received: 28 January 2011 / Revised and accepted: 16 May 2011 / Published online: 7 June 2011

(C) The Author(s) 2011. This article is published with open access at Springerlink.com

\begin{abstract}
High annual microalgae productivities can only be achieved if solar light is efficiently used through the different seasons. During winter the productivity is low because of the light and temperature conditions. The productivity and photosynthetic efficiency of Chlorella sorokiniana were assessed under the worst-case scenario found during winter time in Huelva, south of Spain. The maximum light intensity $\left(800 \mu \mathrm{mol}\right.$ photons $\left.\mathrm{m}^{-2} \mathrm{~s}^{-1}\right)$ and temperature $\left(20^{\circ} \mathrm{C}\right)$ during winter were simulated in a labscale photobioreactor with a short light-path of $14 \mathrm{~mm}$. Chemostat conditions were applied and the results were compared with a temperature-controlled situation at $38^{\circ} \mathrm{C}$ (optimal growth temperature for C. sorokiniana). When temperature was optimal the highest productivity was found at a dilution rate of $0.18 \mathrm{~h}^{-1}\left(P_{\mathrm{v}}=0.28 \mathrm{~g} \mathrm{Kg}^{-1} \mathrm{~h}^{-1}\right)$, and the biomass yield on light energy was high $\left(Y_{\mathrm{x}, \mathrm{E}}=1.2 \mathrm{gmol}^{-1}\right.$ photons supplied). However, at suboptimal temperature, the specific growth rate of $C$. sorokiniana was surprisingly low, not being able to support continuous operation at a dilution rate higher than $0.02 \mathrm{~h}^{-1}$. The slow metabolism under suboptimal temperature resulted in a decline of the light energy requirements of the cells. Consequently, the maximum winter irradiance was experienced as excessive,
\end{abstract}

M. Cuaresma Franco $(\bowtie) \cdot$ M. F. Buffing $\cdot$ M. Janssen •

R. H. Wijffels

Bioprocess Engineering, Wageningen University,

P.O. Box 8129, 6700 EV Wageningen, The Netherlands

e-mail: maria.cuaresma@wur.nl

URL: www.algae.wur.nl

M. Cuaresma Franco $\cdot$ C. Vílchez Lobato

International Centre for Environmental Research (CIECEM),

University of Huelva,

Parque Dunar,

21760 Huelva, Spain leading to a low photosynthetic efficiency and productivity $\left(Y_{\mathrm{x}, \mathrm{E}}=0.5 \mathrm{~g} \mathrm{~mol}^{-1}\right.$ photons supplied, $\left.P_{\mathrm{v}}=0.1 \mathrm{~g} \mathrm{Kg}^{-1} \mathrm{~h}^{-1}\right)$. At suboptimal temperature a higher carotenoid-to-chlorophyll ratio was observed indicating the activation of lightdissipating processes. We conclude that temperature control and/or light dilution during winter time will enhance the productivity.

Keywords Chlorella sorokiniana . Winter irradiance . Suboptimal temperature $\cdot$ Productivity $\cdot$ Biomass yield

\section{Introduction}

In outdoor cultivation microalgae are not only exposed to the daily irradiance cycles but also experience different irradiance levels due to seasonal changes, which depend on the location of cultivation (Eriksen 2008; Jacob-Lopes et al. 2009; Zittelli et al. 2006). In order to reach high yearly productivities light should be efficiently converted into biomass throughout the entire year. In our previous study we assessed the productivity of Chlorella sorokiniana under summer conditions (Cuaresma et al. 2009). In the current paper the performance of $C$. sorokiniana under the most extreme winter circumstances is studied.

To some extent algae can adapt their photosynthetic machinery to changing environmental conditions; this is called (photo)acclimation. It can lead to stable long-term adjustment to the new environmental condition on a phenotypic level (Huner et al. 1998; MacIntyre et al. 2002). But, at high light or low temperature, there is an imbalance between the light absorbed through photochemistry versus the energy utilized through metabolism, which leads to over-excitation of Photosystem II (PSII; Huner et al. 1998). The excitation pressure of PSII can be decreased 
by reducing energy transfer to PSII (photoacclimation) or by dissipating the excess energy as heat (called nonphotochemical quenching (NPQ)). NPQ is a defense mechanism against excessive light and oxidative damage (Muller et al. 2001). Though the photosynthetic machinery is somehow able to acclimate to excessive light energy, all incoming light "wasted" as heat in NPQ is not used for growth (Huisman et al. 2002) which automatically leads to a drop in photosynthetic efficiency.

In addition to light, temperature also affects the photosynthetic activity and the growth of microalgae (Coles and Jones 2000). The photochemical reactions are highly affected by irradiance and are insensitive to temperature (Raven and Geider 1988). In contrast, the biochemical processes are temperature-sensitive, and the absorbed light energy cannot be converted into carbohydrates efficiently at temperatures deviating far from the optimum (Coles and Jones 2000; Dauta et al. 1990; Huner et al. 1998). At low temperatures the turnover of enzymes is reduced, and the metabolic activity of the algae becomes lower. This leads to a lower maximum growth rate and a reduced need of substrate. In the case of light-limited algal growth this substrate is light; therefore, moderate irradiance can already be excessive at low temperatures (Coles and Jones 2000; Dauta et al. 1990). Algae use similar defense mechanism to over-excitation of PSII at low temperatures as at high irradiances (Huner et al. 1998; Maxwell et al. 1994).

In most algae cultivation systems temperature is maintained at its optimum value, although this has an influence on production costs. Avoiding cooling in summer and heating in winter, will result in a reduction in process costs.

The effect of extreme winter conditions on the productivity and photosynthetic efficiency of $C$. sorokiniana under light-limited chemostat conditions was assessed in this work in a short light-path flat panel photobioreactor, one of the most robust designs for microalgae cultivation (Posten 2009). Maximum irradiance and temperature during winter in a horizontal surface $\left(800 \mu \mathrm{mol}\right.$ photons $\left.\mathrm{m}^{-2} \mathrm{~s}^{-1}, 20^{\circ} \mathrm{C}\right)$ in Huelva (Spain, $37^{\circ} 15^{\prime} \mathrm{N} 6^{\circ} 57^{\prime} \mathrm{W}$, PVGIS) were selected to grow $C$. sorokiniana. The influence of temperature control was also tested by applying the optimal growth temperature of C. sorokiniana.

\section{Materials and methods}

Chlorella sorokiniana CCAP 211/8 K (UTEX Culture Collection) was maintained under sterile conditions in Roux flasks containing modified M-8a medium (Cuaresma et al. 2009). The maintenance culture was kept inside a growth chamber at $25^{\circ} \mathrm{C}$ with continuous illumination $\left(150 \mu \mathrm{mol}\right.$ photons $\left.\mathrm{m}^{-2} \mathrm{~s}^{-1}\right)$. The $\mathrm{pH}$ was adjusted to 6.7 , and the cultures were bubbled with $5 \% \mathrm{CO}_{2}$-enriched air.
During the photobioreactor experiments, urea $\left(60 \times 10^{-3} \mathrm{M}\right)$ was used as nitrogen source, and the culture medium had a composition three times higher than the medium used for maintenance (Cuaresma et al. 2009) in order to avoid nutrient limitation.

Experimental conditions A flat panel reactor of $1.7 \mathrm{~L}$ and a light-path of $14 \mathrm{~mm}$ was used in the experiments (Cuaresma et al. 2009). The culture was homogeneously mixed by air bubbling at a flow of $1.5 \mathrm{~L} \mathrm{~L}^{-1}$ culture $\mathrm{min}^{-1}$. The $\mathrm{pH}$ was maintained at 6.7 by adding $\mathrm{CO}_{2}$ via a separate mass flow controller. The gas outflow leaves the reactor via a condenser to prevent evaporation of the culture broth. Temperature was kept constant by a water jacket connected to a thermostat. Temperature, $\mathrm{pH}$, and dissolved oxygen were measured online inside the reactor.

The reactor was illuminated by red light emitting diodes distributed homogeneously over the reactor surface. To simulate winter irradiance at midday in Huelva (Spain, $37^{\circ} 15^{\prime} \mathrm{N} 6^{\circ} 57^{\prime} \mathrm{W}$ ), data from PVGIS (see references) were used. January was selected as reference month, and the maximum irradiance on a horizontal surface was applied to the photobioreactor $\left(800 \mu \mathrm{mol}\right.$ photons $\left.\mathrm{m}^{-2} \mathrm{~s}^{-1}\right)$. The average PFD inside the culture chamber was calculated by measuring the PFD inside the empty reactor with a Licor SA190 quantum sensor at 45 spots distributed homogeneously over the reactor surface. Another Licor SA190 quantum sensor was placed on a reference position in the reactor outer surface, facing the lamps, to continuously measure the received PFD. A correlation factor between the average PFD inside the reactor and the reference PFD could be calculated. With this correlation factor, the PFD was automatically adapted to the desired intensity inside the photobioreactor.

After inoculation, batch cultivation was needed to adapt the microalgae to the light conditions. When biomass density was around $2 \mathrm{~g} \mathrm{Kg}^{-1}$ (approx. $2 \mathrm{~g} \mathrm{~L}^{-1}$ ), chemostat conditions were applied, increasing the dilution rate stepwise. At suboptimal growth temperature, adaptation first to the temperature and then to the dilution rate was needed.

During the steady-state four samples were taken daily from the outflow when operating at optimal growth temperature. Due to the low dilution rate supported at suboptimal growth temperature and the technical pump limitations to supply the corresponding flow rate, the dilution was applied in 2-hour cycles of 50 minutes dilution. In order to have reproducible data, three samples were taken every day at the same time, corresponding with the end of a dilution cycle.

Biomass concentration Dry weight was determined by filtration through glass microfiber filters $(0.7 \mu \mathrm{m}$ pore 
size). Filters were pre-washed with pre-filtered demineralized water, and after filtering the samples, they were washed again to remove salts from the filter retentate. After drying for at least $16 \mathrm{~h}$ at $80^{\circ} \mathrm{C}$, and cooling to room temperature for at least $2 \mathrm{~h}$ in a desiccator, the filters were weighed. Dry weight was determined by differential weight in $\mathrm{g} \mathrm{Kg}^{-1}$ (Cuaresma et al. 2009).

PSII maximum quantum yield: biomass viability

Maximum fluorescence yield $\left(Y_{\mathrm{op}}\right)$ was determined by pulse amplitude modulation (PAM) fluorometry with the saturating-pulse technique. The measurement was done by adapting the samples to dark conditions first for $15 \mathrm{~min}$ to open all reaction centers and avoid measuring nonphotochemical quenching. A chlorophyll fluorometer (PAM-210, Walz, Germany) was used. The measuring light $\left(0.04 \mu \mathrm{mol}\right.$ photons $\mathrm{m}^{-2} \mathrm{~s}^{-1}$ was used to measure the zero fluorescence level $\left(F_{0}\right)$ and a saturating light pulse $\left(1,850 \mu \mathrm{mol}\right.$ photons $\left.\mathrm{m}^{-2} \mathrm{~s}^{-1}\right)$ was applied to measure the maximum fluorescence $\left(F_{\mathrm{m}}\right)$. The yield was calculated by the difference between the background fluorescence $\left(F_{0}\right)$ and the maximal fluorescence after applying a pulse of saturating light $\left(F_{\mathrm{m}}\right)\left(Y_{\mathrm{op}}=F_{\mathrm{m}}-F_{0}\right) / F_{\mathrm{m}} \quad$ (Maxwell and Johnson 2000).

Chlorophyll and carotenoids The chlorophyll and carotenoid content was determined by methanol extraction and spectrophotometry. After a centrifugation step, methanol was added to the pellet and the mixture was placed in an ultrasound bath to disregard the pellet. Subsequently, incubation at $60^{\circ} \mathrm{C}$ first and then at $0^{\circ} \mathrm{C}$ took place to break the cells. After another centrifugation step, the supernatant was collected and analyzed by UV/Visible spectrophotometry. Modified Arnon's equations (Liechtenthaler 1987) were used to calculate the chlorophyll and carotenoid concentrations in the extracts:

$$
\begin{aligned}
& \mathrm{Chl}_{\mathrm{a}}=\left(16.72 \cdot \mathrm{A}_{665}-9.16 \cdot \mathrm{A}_{652}\right) \cdot \text { dilution factor }\left[\mathrm{mg} \mathrm{L}^{-1}\right] \\
& \mathrm{Chl}_{\mathrm{b}}=\left(34.09 \cdot \mathrm{A}_{652}-15.28 \cdot \mathrm{A}_{665}\right) \cdot \text { dilution factor }\left[\mathrm{mg} \mathrm{L}^{-1}\right] \\
& \mathrm{Chl}_{\text {tot }}=\mathrm{Chl}_{\mathrm{a}}+\mathrm{Chl}_{\mathrm{b}}\left[\mathrm{mg} \mathrm{L}^{-1}\right] \\
& \mathrm{Car}_{\text {tot }}=\frac{\text { dilution factor } \cdot 1000 \cdot \mathrm{A}_{470}-1.63 \cdot \mathrm{Chl}_{\mathrm{a}}-104.96 \cdot \mathrm{Ch}_{\mathrm{b}}}{221}\left[\mathrm{mg} \mathrm{L}^{-1}\right]
\end{aligned}
$$

The cell content of chlorophyll and carotenoids are expressed per gram of biomass, calculated based on the dry weight of the samples.

\section{Calculations}

Under chemostat conditions, and during the steady-state, the specific growth rate is equal to the dilution rate applied.
The volumetric productivity $\left(P_{\mathrm{v}}\right)$ can be calculated per total culture weight $\left(M_{\text {reactor }}\right)$ and is the product of the dilution rate $(D)$ and biomass density $\left(C_{\mathrm{x}}\right)$, where dilution rate equals the flow of medium entering the reactor per unit of culture broth.

$P_{\mathrm{v}}=D \cdot C_{\mathrm{x}}=\frac{F}{M_{\text {reactor }}} \cdot C_{\mathrm{x}}\left[\mathrm{g} \cdot \mathrm{Kg}^{-1} \cdot \mathrm{h}^{-1}\right]$

The photosynthetic efficiency of the algae in the reactor can be measured by the biomass yield on light energy $\left(Y_{\mathrm{x}, \mathrm{E}}\right)$, expressed as the amount of light energy that is converted into biomass per mole of photons supplied in the PAR range.

$$
Y_{\mathrm{x}, \mathrm{E}}=\frac{M_{\text {reactor }} \times D \times C_{\mathrm{x}}}{\mathrm{PFD}_{\text {in }} \times 3600 \times \mathrm{A} \times 10^{-6}}[\mathrm{~g} \cdot \mathrm{mol}-1 \text { photons }]
$$

\section{Results and discussion}

Cultivation of $C$. sorokiniana in a flat panel photobioreactor with a light-path of $14 \mathrm{~mm}$ was assayed in terms of biomass productivity and photosynthetic efficiency. Extreme winter conditions (irradiance and temperature) at midday in Huelva, southern Spain, were simulated and compared in terms of productivity and photosynthetic efficiency with optimum growth temperature $\left(T_{\mathrm{opt}}\right)$. In order to gain insight in the yearly production of microalgae, a comparison with the results presented in Cuaresma et al. (2009), where summer irradiance conditions were simulated, is also included in this paper.

When the temperature was below $20^{\circ} \mathrm{C}$ continuous cultivation was not possible at $800 \mu \mathrm{mol}$ photons $\mathrm{m}^{-2} \mathrm{~s}^{-1}$, probably related to the mesophilic character of C. sorokiniana. Only at the maximum winter temperature, $20^{\circ} \mathrm{C}$ (called $T_{\text {sub }}$ ), did the algae show significant growth.

Before the steady-state was reached some days were needed to allow the cells to acclimate. This period was significantly longer at $T_{\text {sub }}$ compared with $T_{\text {opt }}$. At $T_{\text {sub }}$, the biomass concentration decreased drastically upon application of the dilution rate $\left(D=0.02 \mathrm{~h}^{-1}\right)$, and the stabilization of biomass was much slower.

During the experiments no accumulation of dissolved oxygen, which could inhibit the growth at high concentrations, was observed (max. $125 \%$ when $D=0.18 \mathrm{~h}^{-1}$ ).

Productivity and biomass yield

At optimal growth temperature $\left(T_{\mathrm{opt}}=38^{\circ} \mathrm{C}\right)$, and when dilution rate was lower than $0.18 \mathrm{~h}^{-1}$, the productivity increased with increasing dilution rate. However, a higher dilution rate $\left(0.24 \mathrm{~h}^{-1}\right)$ led to a productivity decrease (Fig. 1).

Maximum productivity $\left(P_{\mathrm{v}}=0.28 \mathrm{~g} \mathrm{Kg}^{-1} \mathrm{~h}^{-1}\right)$ therefore was found at a dilution rate of $0.18 \mathrm{~h}^{-1}$. The biomass yield on light 
energy obviously showed the same trend as productivity, with a maximal value of $1.2 \mathrm{gmol}_{\text {photons }}{ }^{-1}$ supplied when $D=$ $0.18 \mathrm{~h}^{-1}$. At high dilution rates the cells experience more light availability since biomass density is low. It leads to a higher photosynthetic efficiency and therefore, productivity. However, when the dilution rate was $0.24 \mathrm{~h}^{-1}$, close to the maximum specific growth rate of $C$. sorokiniana $\left(0.27 \mathrm{~h}^{-1}\right)$, the low biomass density associated to that dilution rate resulted in a bigger loss of photons through the photobioreactor. This leads to a lower photosynthetic efficiency when it is defined as the amount of biomass produced by amount of photons supplied to the system. These results can be related to our previous findings (Cuaresma et al. 2009) where C. sorokiniana was cultivated under continuous irradiance simulating summer conditions $(2100 \mu \mathrm{mol}$ photons $\mathrm{m}^{-2} \mathrm{~s}^{-1}$ ). The optimum dilution rate under summer conditions was $0.24 \mathrm{~h}^{-1}$, but the biomass density associated with that dilution rate was higher when compared with the experiments at $800 \mu \mathrm{mol}$ photons $\mathrm{m}^{-2} \mathrm{~s}^{-1}$. Nevertheless, the photosynthetic efficiency yielded at maximum winter irradiance was higher when compared with the summer experiments (1.2 versus $1.0 \mathrm{~g}$ biomass $\mathrm{mol}^{-1}$ photons). Exposure to a nonoversaturating irradiance during the winter experiments resulted in a higher photosynthetic efficiency when compared with our previous work.

At suboptimal growth temperature $\left(T_{\text {sub }}=20^{\circ} \mathrm{C}\right)$ the only successful dilution rate was $0.02 \mathrm{~h}^{-1}$, due to the much lower specific growth rate of $C$. sorokiniana. It resulted in a productivity of $0.1 \mathrm{~g} \mathrm{Kg}^{-1} \mathrm{~h}^{-1}, 60 \%$ lower than the highest productivity found at $T_{\text {opt }}$. The biomass yield on light energy was also relatively low, with $0.5 \mathrm{~g} \mathrm{~mol}^{-1}$ photons supplied. At suboptimal temperatures the irradiance applied might be experienced as oversaturating, resulting in a higher rate of heat dissipation (NPQ) and therefore a lower photosynthetic efficiency.

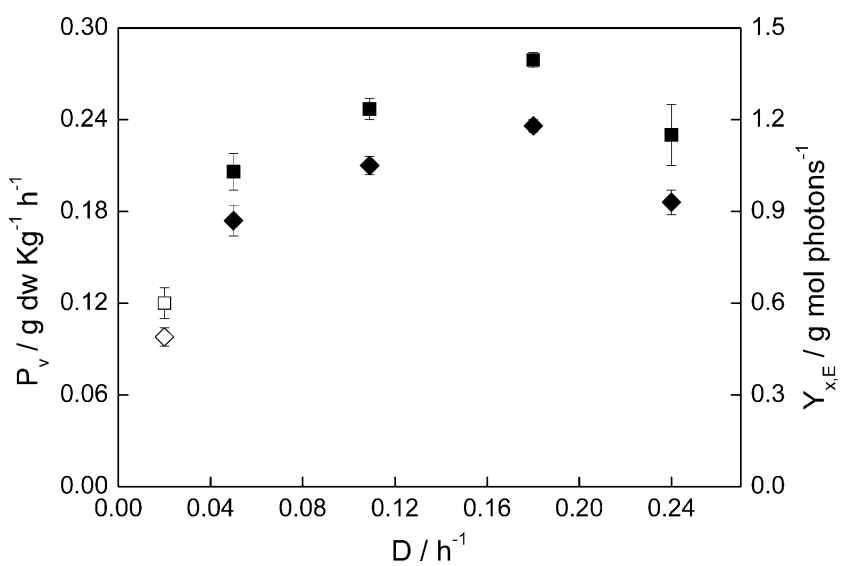

Fig. 1 Volumetric productivity $\left(P_{\mathrm{v}}, \boldsymbol{\square}\right)$ and biomass yield on light energy $\left(Y_{\mathrm{x}, \mathrm{E}}, \downarrow\right)$ during chemostat cultivation at $800 \mu \mathrm{mol}$ photons $\mathrm{m}^{-2}$ $\mathrm{s}^{-1}$ and optimal growth temperature of $C$. sorokiniana $\left(38^{\circ} \mathrm{C}\right)$. Open symbols correspond to suboptimal growth temperature $\left(20^{\circ} \mathrm{C}\right)$
The negative effect of suboptimal growth temperature on algal metabolism and efficiency is strengthened when low temperatures are accompanied by high irradiances, as already stated by different authors (Sorokin and Krauss 1962; Spearing and Karlander 1979; Vonshak and Torzillo 2004; Vonshak et al. 2001). The irradiance tested in this study, $800 \mu \mathrm{mol}$ photons $\mathrm{m}^{-2} \mathrm{~s}^{-1}$, will only be reached around noon during winter outdoor conditions. Since $C$. sorokiniana appeared to be photolimited at $T_{\mathrm{opt}}$, the conditions tested in this work can be considered optimal when controlling the temperature. However, the irradiance was experienced as oversaturating when temperature was suboptimal $\left(T_{\text {sub }}\right)$, therefore it should be considered as the worst-case-scenario during winter cultivation. In this sense, the negative effect of $T_{\text {sub }}$ might be less at other times of the day because of a lower irradiance relative to temperature. Bosma et al. (2007) also assessed the influence of temperature on productivity. They found a positive effect when controlling the temperature at irradiances relatively high.

In this case photoinhibition could be prevented. Heating the culture in the morning also diminishes the negative effect of temperature, leading to a $60 \%$ higher daily productivity as has been already observed by Vonshak et al. (2001).

Biomass density and cell viability

The lower residence time of the cells inside the photobioreactor when increasing the dilution rate led to a lower biomass density as can be seen in Fig. 2. At optimum temperature the biomass concentration ranged from 1 to $4.1 \mathrm{~g} \mathrm{Kg}^{-1}$ and was equal to $6.4 \mathrm{~g} \mathrm{Kg}^{-1}$ at the suboptimal temperature.

According to Cuaresma et al. (2009) the biomass concentration during winter maximal irradiance was twice

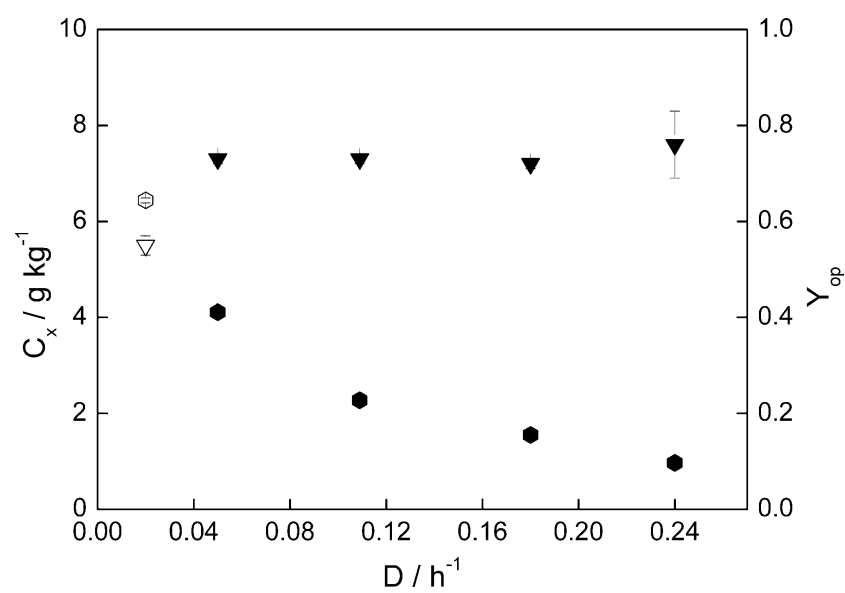

Fig. 2 Biomass concentration $\left.\left(C_{\mathrm{x}},\right)\right)$ and maximum quantum efficiency of PSII $\left(Y_{\mathrm{op}}, \boldsymbol{\nabla}\right)$ during chemostat cultivation at $800 \mu \mathrm{mol}$ photons $\mathrm{m}^{-2} \mathrm{~s}^{-1}$ and optimum growth temperature of $C$. sorokiniana $\left(38^{\circ} \mathrm{C}\right)$. Open symbols correspond to suboptimal growth temperature $\left(20^{\circ} \mathrm{C}\right)$ 
lower if compared with summer maximum irradiance at $0.24 \mathrm{~h}^{-1}$ (2009 Summer versus 2010 Winter). Since light was the only limiting factor at $T_{\mathrm{opt}}$, and no significant photodamage was observed at $800 \mu \mathrm{mol}$ photons $\mathrm{m}^{-2} \mathrm{~s}^{-1}$, it can be concluded that the culture was light-limited under winter conditions. On the other hand, under both simulations (winter and summer), the optimum biomass density was low compared with the high biomass densities found at high irradiance for other algal strains ( $\mathrm{Hu}$ et al. 1998; Meiser et al. 2004; Qiang and Richmond 1996; Qiang et al. 1998). In this sense, high temperature strains such as C. sorokiniana require higher light intensity than other strains with a lower optimum growth temperature (Myers and Graham 1961; Sorokin 1960). Kliphuis et al. (2010) also found a low optimum biomass density for $C$. sorokiniana at high light intensities. Altogether, this indicates that $C$. sorokiniana is not only able to withstand high irradiances but might actually need a high irradiance to achieve high productivities.

The maximum photosynthetic yield of PSII $\left(Y_{\mathrm{op}}\right)$ at the optimum growth temperature remained above 0.7 for all dilution rates applied (Fig. 2) indicating efficient functioning of the photosynthetic machinery and absence of photoinhibition. The absence of significant photodamage at the irradiance tested $\left(800 \mu \mathrm{mol} \mathrm{m} \mathrm{m}^{-2} \mathrm{~s}^{-1}\right)$ is in agreement with the results of Cuaresma et al. (2009) where no photoinhibition of $C$. sorokiniana was observed even at a much higher irradiance $\left(2,100 \mu \mathrm{mol}\right.$ photons $\left.\mathrm{m}^{-2} \mathrm{~s}^{-1}\right)$.

The high biomass concentration found at suboptimal temperature is related to the low specific growth rate, and therefore the low dilution rate applied. As commented before, the slow growth at suboptimal temperatures could be related to the slow algal metabolism, which will result in a decline in substrate requirements, therefore meaningless light in the case of a light-limited chemostat. In this sense, the simulated winter irradiance can support a more dense culture at suboptimal temperature since the individual cells cannot grow fast anyway due to the temperature limitation.

From a photosynthetic point of view, at suboptimal temperatures, the electron sinks will be continuously overreduced due to the slow metabolism. The incoming light will be experienced then as oversaturating, and will result in overexcitation of PSII. A lower photosynthetic efficiency will be expected, and photodamage to PSII is more likely to occur. In this sense, at suboptimal temperatures, a moderate irradiance level can already be counteracting as addressed before. Algae are able to acclimate to excessive irradiance by dissipating the extra light energy as heat via NPQ. This is shown by the low maximum quantum yield of PSII $\left(Y_{\mathrm{op}}=0.5\right)$, which was below the typical value for healthy cells $\left(Y_{\mathrm{op}}=0.7\right)$. This low $Y_{\mathrm{op}}$ was also reflected in the low biomass yield, and productivity reached at $T_{\text {sub }}$.
In this study a large deviation from $T_{\mathrm{opt}}$ was applied $\left(\Delta T=18^{\circ} \mathrm{C}\right)$, which led to a $30 \%$ decrease in $Y_{\text {op }}$ compared with $T_{\text {opt }}$. This is in accordance with Grobbelaar (2007) who also reported a $30 \%$ drop in $Y_{\text {op }}$ at midday when cultivating Spirulina platensis $10^{\circ} \mathrm{C}$ below the optimum growth temperature. Moreover, Maxwell et al. (1994) also found that growth of Chlorella vulgaris had the same photosynthetic response to low temperature as to high irradiances. Thus (over)saturating light conditions at suboptimal temperatures lead to photoinhibition and a decrease in the photosynthetic efficiency.

\section{Cell pigmentation}

At optimal temperature $\left(T_{\mathrm{opt}}\right)$, the total chlorophyll content ranged from 35.4 to $19.4 \mathrm{mg} \mathrm{g}^{-1}$ and the total carotenoids content from 6.7 to $3.7 \mathrm{mg} \mathrm{g}^{-1}$. The total pigment content per unit of biomass decreased with increasing dilution rate (Fig. 3) when the culture experienced a higher average irradiance due to the lower biomass concentration. At higher biomass concentrations, higher pigment content is expected to compensate for the increase in photolimitation, a process called photoacclimation.

The pigment content at suboptimal temperature $(31.2 \mathrm{mg}$ and $6.8 \mathrm{mg}$ carotenoids $\mathrm{g}^{-1} \mathrm{dw}$ ) was lower than expected considering that the biomass concentration was higher than the highest biomass concentration achieved at $T_{\text {opt }}$. The low metabolic activity and thereby the lower requirement of light energy at suboptimal temperature could explain that observation.

In contrast to the chlorophyll content the carotenoid content at suboptimal temperature was the same when compared with $T_{\text {opt }}$. This resulted in a slightly higher ratio of carotenoids to chlorophyll at $T_{\text {sub }}(16 \%$ higher). This is

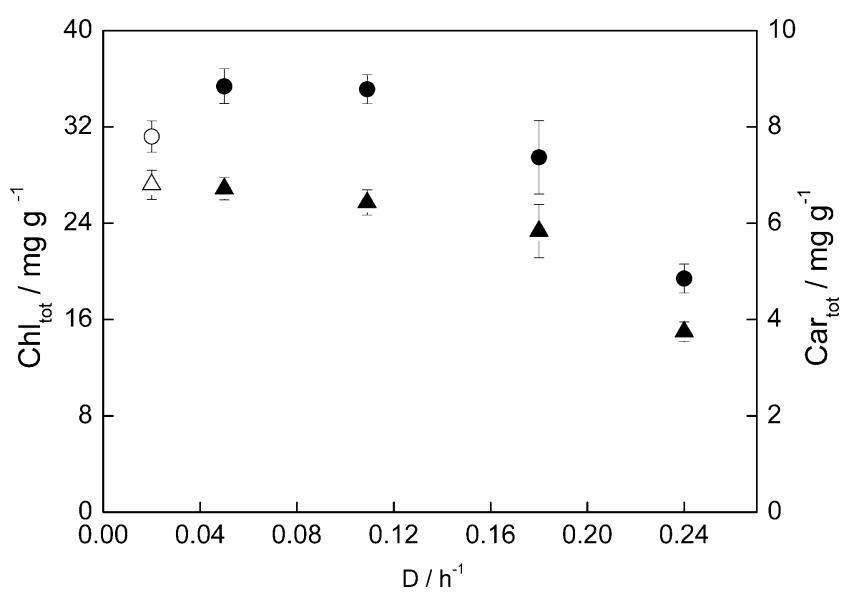

Fig. 3 Total chlorophyll $\left(\mathrm{Chl}_{\text {tot }}, \bullet\right)$ and carotenoids content $\left(\mathrm{Car}_{\text {tot }}\right.$, $\boldsymbol{\Delta})$ during chemostat cultivation at $800 \mu \mathrm{mol}$ photons $\mathrm{m}^{-2} \mathrm{~s}^{-1}$ and optimum growth temperature of $C$. sorokiniana $\left(38^{\circ} \mathrm{C}\right)$. Open symbols correspond to suboptimal growth temperature $\left(20^{\circ} \mathrm{C}\right)$ 
probably related to the higher NPQ since the carotenoids also function as antioxidants and play a role in dissipation of excessive light as heat (Niyogi et al. 1997). At the optimum growth temperature the carotenoid/chlorophyll ratio was similar under all the dilution rates assayed, which seems to indicate that no extra photoprotective activity from the carotenoids was needed.

\section{Conclusions}

The strong influence of temperature on algal productivity during winter cultivation was confirmed by this study. Suboptimal growth temperatures lead to a low specific growth rate. Therefore, a low productivity was found at $20^{\circ} \mathrm{C}$, the maximal winter temperature, for $C$. sorokiniana $\left(0.12 \mathrm{~g} \mathrm{Kg}^{-1} \mathrm{~h}^{-1}\right)$. Biomass yield on light energy was also low, $0.5 \mathrm{~g} \mathrm{~mol}^{-1}$ photons. The slow metabolism and the higher need of NPQ to dissipate the excessive light absorbed resulted in a lower photosynthetic efficiency of C. sorokiniana at suboptimal temperatures.

Due to the over-saturating irradiance experienced by the algal cells at suboptimal temperature a higher carotenoid-tochlorophyll ratio was observed, which was probably related to the higher levels of heat dissipation (NPQ).

Temperature control during winter time could clearly enhance the productivity and photosynthetic efficiency of C. sorokiniana. At optimal growth temperature, the productivity reached at maximal winter irradiance $\left(800 \mu \mathrm{mol}\right.$ photons $\left.\mathrm{m}^{-2} \mathrm{~s}^{-1}\right)$ was high when compared with suboptimal temperature, but about half of the productivity found with the same cultivation system at maximal summer irradiance (Cuaresma et al. 2009). Nevertheless, the biomass yield on light energy was higher at maximal winter irradiance $\left(Y_{\mathrm{x}, \mathrm{E}}=1.2 \mathrm{~g} \mathrm{dw} \mathrm{mol}^{-1}\right.$ photons supplied) than at summer irradiance $\left(Y_{\mathrm{x}, \mathrm{E}}=1.0 \mathrm{~g} \mathrm{dw} \mathrm{mol}^{-1}\right.$ photons supplied). The low winter irradiance resulted in a more efficient conversion of the available light biomass (higher $\left.Y_{\mathrm{x}, \mathrm{E}}\right)$ by $C$. sorokiniana when temperature is controlled. However, the lower photons availability during winter time led to a lower volumetric productivity when compared with summer irradiance, suggesting that the photobioreactor was operated in the photolimited regime.

During winter, the suboptimal temperature is the main factor reducing metabolic rates and, consequently, photosynthetic efficiency at relatively high irradiance (around noon). Higher temperatures than $20^{\circ} \mathrm{C}$ would lead to a higher productivity, therefore temperature control will result in higher winter productivities. Reduction of irradiance at the photobioreactor surface, on the other hand, might be an attractive alternative to temperature control in outdoor cultivation during winter time.
Acknowledgments This work was financially supported by the University of Huelva and Junta de Andalucía (Proyectos de Excelencia, AGR-4337) in Spain, and a SenterNovem subsidy (The Netherlands) in the frame of the "Unieke Kans Regeling" program, grant number 02013, with Technogrow BV as industrial partner.

Open Access This article is distributed under the terms of the Creative Commons Attribution Noncommercial License which permits any noncommercial use, distribution, and reproduction in any medium, provided the original author(s) and source are credited.

\section{References}

Bosma R, van Zessen E, Reith JH, Tramper J, Wijffels RH (2007) Prediction of volumetric productivity of an outdoor photobioreactor. Biotechnol Bioeng 97:1108-1120

Coles JF, Jones RC (2000) Effect of temperature on photosynthesislight response and growth of four phytoplankton species isolated from tidal freshwater river. J Phycol 36:7-16

Cuaresma M, Janssen M, Vílchez C, Wijffels RH (2009) Productivity of Chlorella sorokiniana in a short light-path (SLP) panel photobioreactor under high irradiance. Biotechnol Bioeng 104:352-359

Dauta A, Devaux J, Piquemal F, Boumnich L (1990) Growth rate of four freshwater algae in relation to light and temperature. Hydrobiologia 207:221-226

Eriksen NT (2008) The technology of microalgal culturing. Biotechnol Lett 30:1525-1536

Grobbelaar JU (2007) Photosynthetic characteristics of Spirulina platensis grown in commercial-scale open outdoor raceway ponds: what do the organisms tell us? J Appl Phycol 19:591-598

Hu Q, Kurano N, Kawachi M, Iwasaki I, Miyachi S (1998) Ultrahighcell-density culture of a marine green alga Chlorococcum littorale in a flat-plate photobioreactor. Appl Microbiol Biotechnol 49:655-662

Huisman J, Matthijs HCP, Visser PM, Balke H, Sigon CAM, Passarge J, Weissing FJ, Mur LR (2002) Principles of the light-limited chemostat: theory and ecological applications. Antonie Leeuwenhoek 81:117-133

Huner NPA, Öquist G, Sarhan F (1998) Energy balance and acclimation to light and cold. Trends Plant Sci 3:224-230

Jacob-Lopes E, Gimenes Scoparo CH, Ferreira Lacerda LMC, Teixeira Franco T (2009) Effect of light cycles (night/day) on $\mathrm{CO}_{2}$ fixation and biomass production by microalgae in photobioreactors. Chem Eng Process 48:306-310

Kliphuis AMJ, de Winter L, Vejrazka C, Martens DE, Janssen M, Wijffels RH (2010) Photosynthetic efficiency of Chlorella sorokiniana in a turbulently mixed short light-path photobioreactor. Biotechnol Prog 26:687-696

Liechtenthaler H (1987) Chlorophylls and carotenoids: pigments of photosynthetic biomembranes. Methods Enzymol 148:350-382

MacIntyre HI, Kana TM, Anning T, Geider RJ (2002) Review: Photoacclimation of photosynthesis irradiance response curves and photosynthetic pigments in microalgae and cyanobacteria. J Phycol 38:17-38

Maxwell K, Johnson GN (2000) Review: Chlorophyll fluorescence a practical guide. J Exp Bot 51:659-668

Maxwell DP, Falk S, Trick CG, Huner NPA (1994) Growth at low temperature mimics high-light acclimation in Chlorella vulgaris. Plant Physiol 105:535-543

Meiser A, Schmid-Staiger U, Trösch W (2004) Optimization of eicosapentaenoic acid production by Phaeodactylum tricornutum in the flat panel airlift (FPA) reactor. J Appl Phycol $16: 215-225$ 
Muller P, Li X-P, Niyogi KK (2001) Non photochemical quenching. A response to excess light energy. Plant Physiol 125:1558-1566

Myers J, Graham JR (1961) On the mass culture of algae. III. Light diffusers; High vs low temperature Chlorellas. Plant Physiol 36:342-346

Niyogi KK, Björkman O, Grossman AR (1997) The roles of specific xantophylls in photoprotection. Proc Natl Acad Sci USA 94:14162-14167

Posten C (2009) Design principles of photo-bioreactors for cultivation of microalgae. Eng Life Sci 9:165-177

PVGIS: Photovoltaic Geographical Information System. European Commission. Joint Research Centre. Institute for Energy, Renewable Energy Unit, via Fermi 2749, TP 450, I-21027 Ispra (VA), Italy. http://re.jrc.ec.europa.eu/pvgis/

Qiang H, Richmond A (1996) Productivity and photosynthetic efficiency of Spirulina platensis as affected by light intensity, algal density and rate of mixing in a flat plate photobioreactor. J Appl Phycol 8:139-145

Qiang H, Zarmi Y, Richmond A (1998) Combined effect of light intensity, light-path and culture density on output rate of Spirulina patensis (cyanobacteria). Eur J Phycol 33:165-171
Raven JA, Geider RJ (1988) Temperature and algal growth. New Phytol 110:441-461

Sorokin C (1960) Kinetic studies of temperature effects on the cellular level. Biochim Biophys Acta 38:197-204

Sorokin C, Krauss RW (1962) Effects of temperature and illuminance on Chlorella growth uncoupled from cell division. Plant Physiol pp. $37-42$

Spearing AM, Karlander EP (1979) Effects of light and low temperatures on chlorophyll content and metabolism of Chlorella sorokiniana Shihira and Krauss. Environ Exp Bot 19:237-243

Vonshak A, Torzillo G (2004) Environmental stress physiology. In: Richmond A (ed) Handbook of microalgal culture: Biotechnology and Applied Phycology. United Kingdom, Blackwell Science, pp 57-82, Chapter

Vonshak A, Torzillo G, Masojídek J, Boussiba S (2001) Sub-optimal morning temperature induces photoinhibition in dense outdoor cultures of the alga Monodus subterraneus (Eustigmatophyta). Plant Cell Environ 24:1113-1118

Zittelli GC, Rodolfi L, Biondi N, Tredici MR (2006) Productivity and photosynthetic efficiency of outdoor cultures of Tetraselmis suecica in annular columns. Aquaculture 261:932-943 